\title{
Chylous Ascites due to Mantle Cell Lymphoma
}

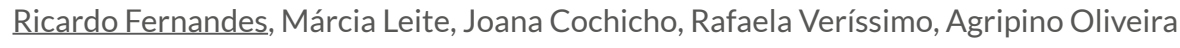 \\ Internal Medicine Department, Centro Hospitalar de Vila Nova de Gaia-Espinho, Portugal
}

Received: 26/02/2017

Accepted: 05/03/2018

Published: 03/04/2018

How to cite this article: Fernandes R, Leite M, Cochicho J, Veríssimo R, Oliveira A. Chylous ascites due to mantle cell lymphoma. EJCRIM 2018;5: doi:10.12890/2018 000871.

Conflicts of Interests: The Authors declare that there are no competing interests.

This article is licensed under a Commons Attribution Non-Commercial 4.0 License

\section{ABSTRACT}

Chylous ascites is rare and results in accumulation of lymph in the abdominal cavity, due to several mechanisms. The ascitic liquid is milky because of the high concentration of triglycerides ( $>200 \mathrm{mg} / \mathrm{dl}$ ). The higher incidence compared to the past is explained by increased survival of patients with cancer and more aggressive surgery. We describe the case of an 87-year-old man admitted to the geriatric ward due to general oedema, chylous ascites and loss of weight, explained by mantle cell lymphoma.

\section{LEARNING POINTS}

- Chylous ascites is more frequent in trauma, but in some cases may be related to obstruction of the thoracic duct by retroperitoneal fibrosis, pancreatitis or neoplasms.

- It is a progressive, difficult to manage condition, with a spectrum of treatment ranging from a special diet to surgery.

- Its prognosis depends fundamentally on the predisposing condition.

\section{KEYWORDS}

Chylous ascites, mantle cell lymphoma, ascites

\section{INTRODUCTION}

Chylous ascites is a relatively rare form of ascites resulting in the accumulation of lymph in the abdominal cavity. It is characterized by a milky ascitic liquid with an elevated concentration of triglycerides $(>200 \mathrm{mg} / \mathrm{dl})^{[1]}$. Although there have been no recent large epidemiological studies, it is generally believed that its incidence has increased due to the longer survival of patients with cancer and more aggressive abdominal and cardiothoracic interventions.

The main pathophysiological mechanisms postulated for this condition are: (a) obstruction of the flow of lymph caused by external pressure leading to leakage from dilated subserosal lymphatic channels into the peritoneal cavity; (b) lymph exuding through the walls of dilated retroperitoneal vessels without valves, which leak fluid through a fistula into the peritoneal cavity, as in congenital lymphangiectasia; and (c) traumatic obstruction of the thoracic duct ${ }^{[2]}$.

We describe a case of lymphoproliferative disease presenting as chylous ascites.

\section{CASE REPORT}

An 87-year-old man presented with abdominal distension, peripheral oedema and constitutional symptoms of fatigue, anorexia and involuntary weight loss (12.7\%). His medical history was positive for hypertension and alcohol consumption of $36 \mathrm{~g}$ per day for the last 40 years. There was a positive family history of gastrointestinal cancer.

On physical examination, the patient had obvious ascites (grade III) and lower extremity oedema. Vital signs were normal. There was no 
jaundice or scleral icterus and also no signs of chronic liver disease, palmar erythema, enlarged parotids or gynecomastia. The abdomen was distended with bulging flanks, a fluid wave, shifting dullness and signs of hepatofugal collateral circulation. No abdominal organomegaly was detected. Cardiovascular and pulmonary examinations were normal. Pitting oedema was present in both legs up to the thighs. Two enlarged axillary lymph nodes were also detected. Initial investigation revealed a widened mediastinum on chest X-ray (Fig. 1).

Initial laboratory tests showed a normal haemogram and blood smear, erythrocyte sedimentation rate of $50 \mathrm{~mm} / \mathrm{hour}$ (normal values: 0-20), C-reactive protein of $5.74 \mathrm{mg} / \mathrm{dl}$, lactate dehydrogenase (LDH) of $370 \mathrm{IU} / \mathrm{l}$ (normal values: 135-225) and triglycerides of $88 \mathrm{mg} / \mathrm{dl}$. Serum protein electrophoresis showed: albumin 3.02 (normal values: 3.9-5.1 mg/dl), alpha $10.23 \mathrm{~g} / \mathrm{dl}$, alpha $20.86 \mathrm{~g} / \mathrm{dl}$, beta (pt) $0.54 \mathrm{~g} / \mathrm{dl}$, and gamma $1.66 \mathrm{~g} / \mathrm{dl}$. Immunoglobulin G was elevated (1640.0 mg/dl), but immunoglobulins A and M were normal (Table 1).

Abdominal paracentesis revealed a milky peritoneal fluid with albumin of $1.1 \mathrm{~g} / \mathrm{dl}$ and a serum-ascites albumin gradient of $2.1 \mathrm{~g} / \mathrm{dl}$. The ascitic fluid contained 1461 leucocytes/ $\mu$ l (79\% mononuclear cells), triglycerides $2298 \mathrm{mg} / \mathrm{dl}$, glucose $85 \mathrm{mg} / \mathrm{dl}$, adenosine deaminase (ADA) $34 \mathrm{IU} / \mathrm{I}$ and LDH $174 \mathrm{IU} / \mathrm{l}$. Culture was negative as was cytological examination for malignant cells. Further testing revealed an elevated B2microglobulin of $11.7 \mathrm{mg} / \mathrm{l}$ (normal values 0.8-2.2). Viral serologies (HIV, HCV, HBV) were also negative. In the urinalysis no pathological alteration was found, except for low grade proteinuria. Serum electroimmunofixation was positive for IgM lambda.

Subsequent investigation with computerized tomography (CT) revealed multiple thoracic and abdominal lymphadenopathies forming large conglomerates, the largest abdominal mass having a diameter of $20 \mathrm{~cm}$ (Fig. 2).

The patient began oral furosemide $40 \mathrm{mg}$ and spironolactone $100 \mathrm{mg}$ with ascites volume reduction and better symptom control.

Excisional biopsy of the axillary adenopathy revealed mantle cell lymphoma with a diffuse architectural pattern, classic type with a proliferative index of $20 \%$ (Fig. 3). Bone marrow and gastrointestinal involvement was not investigated since treatment would not be effective. Stage III/IV mantle cell non-Hodgkin lymphoma was diagnosed and after discussing the goals of treatment, palliative chemotherapy according the PEPC protocol (prednisolone $20 \mathrm{mg}$ once a day (OD), cyclophosphamide $50 \mathrm{mg}$ OD, etoposide $50 \mathrm{mg}$ OD and procarbazine 50 $\mathrm{mg}$ OD). The patient died from pneumonia 1 month after beginning treatment.
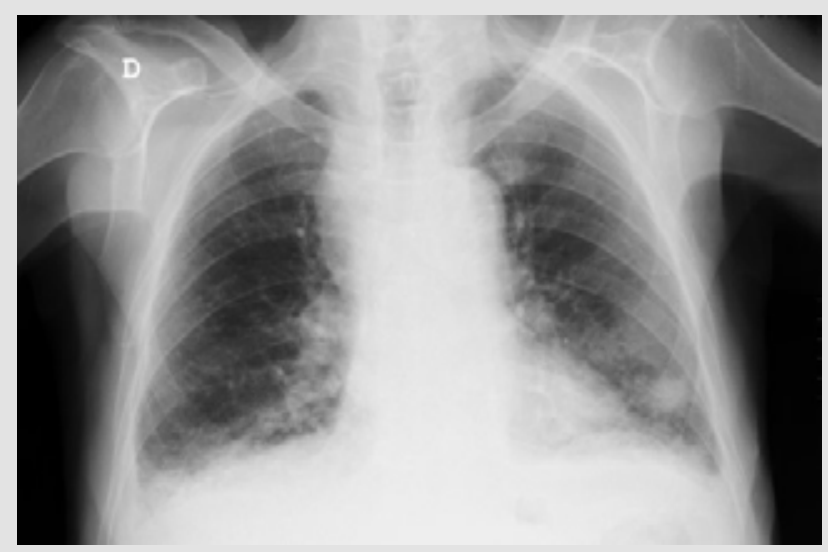

Figure 1. Enlargement of the mediastinum.

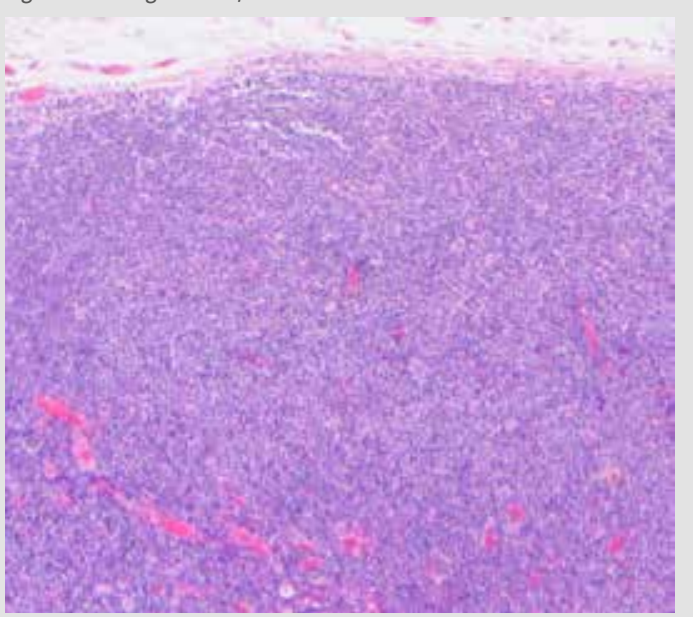

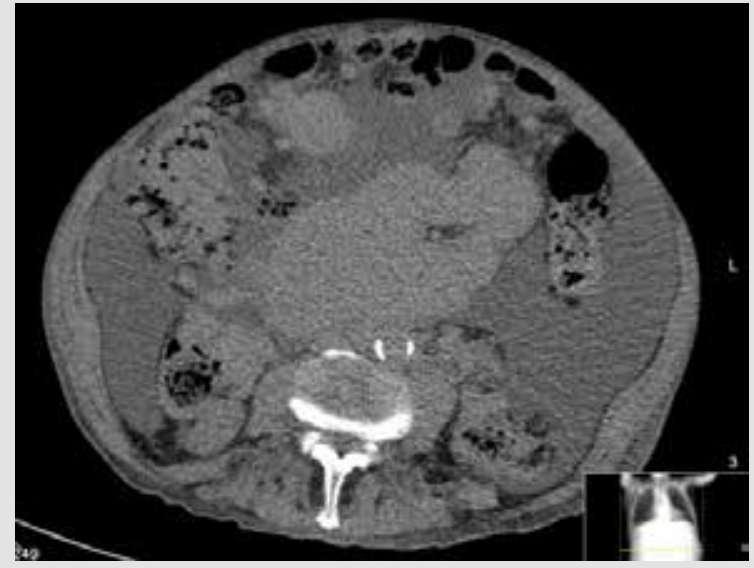

Figure 2. Abdominal CT scan showing the abdominal conglomerate
Figure 3. Histology of the axillary lymph node showing a diffuse architectural pattern and varying cytology with a proliferative index of $20 \%$ 


\begin{tabular}{|c|c|c|c|c|c|}
\hline Analytic parameters & Admission & Day 2 & Day 3 & Day 9 & Normal value \\
\hline Haemoglobin (g/dl) & 12.32 & 11.3 & 11.3 & 11.5 & $13-18$ \\
\hline Erythrocytes $\left(\times 10^{12}\right)$ & 4.05 & 3.67 & 3.67 & 3.78 & $4.4-5.9$ \\
\hline Haematocrit (\%) & 37.1 & 33.1 & 33.1 & 34.8 & $40-52$ \\
\hline Leucocytes $\left(x 10^{3}\right)$ & 8.55 & 6.09 & 5.60 & 6.82 & $3.8-10.6$ \\
\hline Neutrophils (\%) & 78.5 & 73.6 & 71.1 & 71.3 & $1.3-8.8$ \\
\hline Lymphocytes (x103/\%) & $1.13 / 13.2$ & $0.95 / 15.6$ & $0.84 / 15.0$ & $1.25 / 18.3$ & $1.0-4.8$ \\
\hline 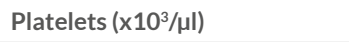 & 296 & 280 & 296 & 360 & $150-440$ \\
\hline Sedimentation velocity $(\mathrm{mm} / \mathrm{s})$ & - & 50 & - & - & $0-15$ \\
\hline Glucose (mg/dl) & 86 & 76 & - & - & $60-100$ \\
\hline Creatinine (mg/dl) & 1.05 & 1.33 & 1.49 & 1.53 & $0.67-1.17$ \\
\hline Urea (mg/dl) & 49 & 51 & 49 & 95 & $17-50$ \\
\hline Sodium (mmol/l) & 135 & 134 & 134 & 131 & 136-145 \\
\hline Potassium (mmol/l) & 5.14 & 5.54 & 5.19 & 4.94 & $3.5-5.0$ \\
\hline Chloride (mmol/l) & 49 & 51 & 91 & 87.0 & $17-50$ \\
\hline Calcium (mg/dl) & - & 8.2 & - & - & $8.4-9.7$ \\
\hline Uric acid (mg/dl) & - & - & 8.40 & - & $0.2-5.7$ \\
\hline Total bilirrubin (mg/dl) & 0.46 & 0.41 & - & 0.34 & $0.1-1.1$ \\
\hline $\begin{array}{l}\text { Lactacte dehydrogenase } \\
\text { (U/I) }\end{array}$ & 370 & 300 & 258 & 273 & $135-225$ \\
\hline $\begin{array}{l}\text { Aspartate aminotransferase } \\
\text { (AST - U/I) }\end{array}$ & 33 & 27 & 26 & 36 & $4-33$ \\
\hline $\begin{array}{l}\text { Alanine aminotransferase } \\
\text { (ALT - U/I) }\end{array}$ & 11 & 11 & 12 & 21 & $4-50$ \\
\hline $\begin{array}{l}\text { Gamma glutamyl transferase } \\
\text { (GGT - U/I) }\end{array}$ & 25 & 19 & 19 & 26 & $5-61$ \\
\hline Alkaline phosphatase (U/I) & 93 & 87 & 83 & 91 & $40-129$ \\
\hline Total proteins (g/dl) & - & 6.3 & 6.5 & - & $6.4-8.3$ \\
\hline Albumin (g/dl) & 3.3 & - & 3.1 & - & $3.4-4.8$ \\
\hline Triglycerides (mg/dl) & 98 & 88 & 100 & - & $<200$ \\
\hline $\begin{array}{l}\text { C reactive protein } \\
\text { (CRP - mg/dl) }\end{array}$ & 5.13 & 5.74 & 4.01 & 3.69 & $0-0.5$ \\
\hline B 12 vitamin $(\mathrm{pg} / \mathrm{ml})$ & - & - & 304.7 & - & 197-771 \\
\hline Folic acid (ng/ml) & - & - & 1.9 & - & $4.6-18.7$ \\
\hline Antinuclear antibodies (ANA) & - & $<1 / 160$ & - & - & $<1 / 160$ \\
\hline B2-microglobulin (mg/l) & - & 11.7 & - & - & $0.8-2.2$ \\
\hline Immunoglobulin G & \multicolumn{2}{|c|}{1640} & - & 2030 & $680-1450$ \\
\hline Immunoglobulin A & - & 389 & - & 427 & $83-407$ \\
\hline Immunoglobulin M & - & 115 & - & 131 & $34-214$ \\
\hline Kappa chain & - & - & - & 48 & $200-440$ \\
\hline Lambda chain & - & - & - & 344 & $110-240$ \\
\hline Kappa/lambda relationship & - & - & - & 1.4 & $1.35-2.70$ \\
\hline
\end{tabular}




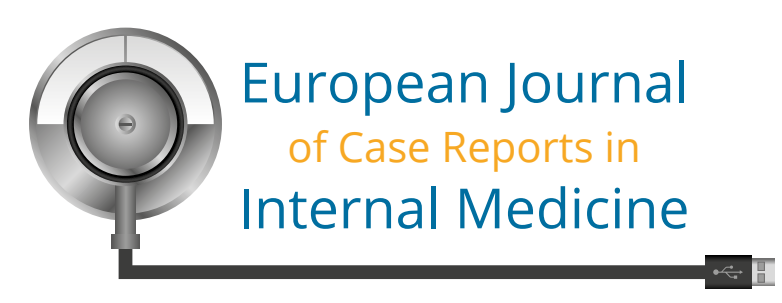

\section{DISCUSSION}

The standard treatment for chylous ascites has not yet been established. However, the best results have been obtained by treating the underlying cause (in this specific case a lymphoma). For patients in whom the cause is not found or who do not respond to treatment of the underlying cause, nutritional therapy with a high-protein and low-fat diet with medium-chain triglycerides is recommended. Other approaches include frequent paracentesis, surgery (using sclerosing agents and suture ligation of the thoracic duct) or peritoneovenous shunting ${ }^{[3]}$. Our patient had concomitant portal hypertension, the underlying mechanism being pre-hepatic due to extrinsic compression of portal circulation. Although he responded favourably to diuretics, he died due to a nosocomial pneumonia. This case highlights the fact that although most cases of chylous ascites are related to trauma, some may be due to other causes such as lymphoproliferative diseases, pancreatitis $^{[2]}$ or retroperitoneal fibrosis ${ }^{[4]}$.

\section{REFERENCES}

1. Almakdisi T, Massoud S, Makdisi G. Lymphomas and chylous ascites: review of the literature. Oncologist 2005;10:632-635.

2. Baban CK, Murphy M, O'Sulleabháin C, O'Hanlon D. Chylous ascites as a consequence of idiopathic pancreatitis. BMJ Case Rep 2014; doi:10.1136/bcr-2013-200132.

3. Al-Busafi SA, Ghali P, Deschênes M, Wong P. Chylous ascites: evaluation and management. ISRN Hepatol 2014;2014:240473.

4. Ur Rahman A, Ramaraj R, Humphreys E, Slowinska E. Retroperitoneal fibrosis as a cause of chylous ascites. ACG Case Rep J 2017;4:e115. 